\title{
A Soft Corner Approach to Think/Act for Conservation Defining Wildlife Conservation and Law Enforcement Initiatives of Nepal Police
}

- Devendra Subedi*

A serious statement human have always hunted. We need to understand first and clear the confusion that food, clothing, tools, and shelter are mainly provided by harvesting wild plants and animals. Human are animals, and like all species, are totally dependent on natural resources for survival. Human, have always been, and always will be a part of, and not apart from nature. Whether, they choose to eat domesticated fruits and vegetables, processed foods, wild animals and plants or farmed livestock, the environment (nature) is the source of all these foods.

Human evolved as omnivore creatures are also predators like bears, raccoons, and painted turtles. All predators have developed specialized physical features for hunting through time, such as talons, claws or venom but human use their intelligence as an advantage when hunting as they lack such feature from hunting in groups using clubs and stones to the current use of modern firearms, human have been successful at obtaining animal and plant foods from the wild.

But do human really need to hunt? In today's technological society, there is fresh product from Meat-Ko Plus the chicken sausage, buff sausages, locally-grown greenhouse tomatoes, and many fast-food outlets. Aside from a few aboriginal cultures that still depend on hunting and gathering, who needs to hunt to survive?

In other parts of the world, many aboriginal people still hunt as part of their cultural and social traditions. We also have the records that many hunt as a part of chosen lifestyle that often includes activities, such as gardening, fishing, trapping, and cutting firewood. All these people hunt because they need and want to; it provides nutritious food for the table, allows one to provide for oneself, and fosters closeness with the environment. But how does modern hunting impact on today's wildlife? Can human kill wildlife and still expect healthy populations of animals to exist into the future?

All plant and animal species have evolved so that each has a strategy that helps to ensure their future survival. Many species produce offspring more than available habitat can support. There is only so much food and shelter available, particularly during the winter. These "surplus" animals die from a variety of causes - starvation, disease, predation, or accidents. Old age is seldom an option in the wild. Only those that elude predators, find enough food to sustain them, escape disease, and avoid accidents, will survive. Natural mortality factors help ensures that there is room for next year's crop of young. By being fruitful and multiplying, nature increases the chances that enough animals, young and adult, will survive to reproduce and perpetuate themselves next year.

Human predation on wildlife through hunting, is strictly controlled by licence numbers, authority and permission limits. Part of the science of wildlife management is predicting safe harvest levels. Controlled hunting is not detrimental to animal populations. Modern wildlife management ensures that enough animals are left each year to replace those harvested by human. When controlled hunting takes individual animals out of the population, they are replaced by others of their kind. Regulated hunting is an example of sustainable use of a renewable natural resource.

Hunting does have a dark past. Following the onset of Neo Nepal in King Drabay's dynasty, unregulated market hunting for hides, meat, feathers, and eggs was disastrous. I don't know when we witnessed the first regulation of hunting in Nepal. Hunters lobbied hard for these changes. Laws were established as early attempts at protection and have been increased to the point today where there is a very complex arrangement of regulations designed

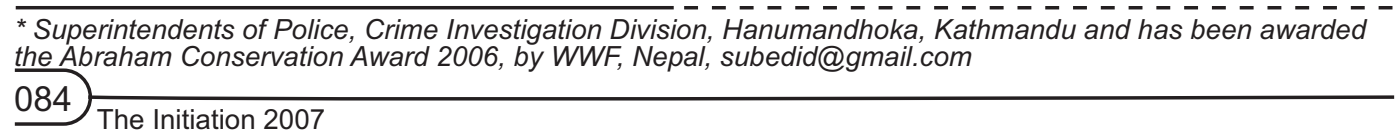


to conserve wildlife resource. For today's wildlife agencies, conserving wildlife populations is the number one priority. Where numbers are sufficient.

The single greatest threat to wildlife is habitat loss. Importance of the wildlife habitat let's take a simple example of bald eagles nest in mature forest areas of CHARKOSHE JUNGLE in terai Nepal close to water where they capture fish for food. Eagles prefer tall trees growing on the shore or in ravines. Such specialized nesting areas are becoming hard to come by, and if these habitats are not maintained, bald eagles may disappear from the Nepali landscape.

In the fall, hundreds of thousands of migratory birds (TAL CHARA) descend on the tidal mud flats of the Bay of NEPALI Terai to feed and accumulate the fat reserves required for their long journey toward south. If these mudflats are disturbed, the entire migration pattern of these birds would be upset.

Without habitat, there is no wildlife. Human encroachment, pollution, draining of wetlands, and development are taking land out of production for wildlife. When animals cease to exist because of habitat loss, they are gone - forever! Habitat destruction guarantees species disappearances and wildlife extinctions.

Non-hunted and endangered species, as well as the traditional game animals (like HATTI POLO in Chitwon) benefit from habitat protection and restoration programs.

Hunting is not for everyone. However, in our modern, computer-age society, there are those who still choose to provide nutritious meat for their families, enjoy the natural experience of the RATTE, and desire to remain a part of the natural cycle of life and death. Hunting is a chosen lifestyle and one that is in harmony with the human role in nature. Hunting is not destructive to the natural world. Controlled hunting and gathering of wild foods are environmentally friendly. It is too bad that more human activities cannot legitimately make the same claim.

\section{Understanding Wildlife Enforcement}

The importance of wildlife activity - hunting, fishing, trapping, watching birds, photographing wildlife, reading outdoor and nature books and magazines, or viewing films and television programs on wildlife themes. On the other side Wildlife poaching is one of the biggest complaints for Departments working in the field of Natural Resources conservation, District forest office, protected areas and Nepal Police enforcement offices receive as in frequency. Poaching includes not only hunting wildlife illegally, but also taking the life of wild animals for the black money.

Our grave concern is that Nepal has been slowly developing as a major hub of the transit point for many types of wildlife crimes and that we don't deny. Wildlife enforcement is effective where there is strong community involvement. Poachers must feel that they have to watch out for everyone, not just the police officer. Anyone may become aware of wildlife violations, but it is important that they pass the information on to local police officers. A rumor or information that seems insignificant to be the missing link in an investigation or the beginning of a major operation.

It is not uncommon for officers to receive information that a person has illegal wildlife in the contact or connection or the wall hanging. The action taken depends on the circumstances and the information. Police Officers must have legal grounds to obtain a search warrant. Even if no action is taken the information is recorded and it may help the officer the next time when a call is received. If you are willing to give your name and go to court to give evidence, the officer may be able to lay a charge using you as a witness.

The public could report illegal activity through the department's Report any crime by calling 100 or through Crime Stoppers at 01-4261707 at the Crime Division. You do not have to give your name and you could be paid for your information. Hunters and non-hunters are asked to provide community support by reporting any information they become aware 
of. Poachers are not hunters, they are criminals. Only a small percentage of people are involved in this illegal activity. Let us put some record retrieved from our Division, our team efforts several time have attempted for the intelligence of wildlife crime control and have apprehended many offenders and proceeded for the concerned office and authority for the justice.

The following is an overview of some of the regulations.

With certain exceptions no person shall hunt/kill/sell wildlife and wild life products at any means (National Park and Wildlife Conservation Act 1973).

The CITIES treaty 1975 states the endangered species and the safeguard of the world heritage, where Nepal is a signatory party.

IUCN, Red data book 1994, Where Nepal is a state member of IUCN

Nepal forest Act-1992

"Endangered" is a term used to describe wild animals and plants that are in some kind of peril. Human are by definition associated with this danger, because we disturb wildlife and alter its habitats.

Rare species are few in number or found only in very restricted areas; although not in immediate danger, they could be at any time. Threatened species are likely to become endangered if the pressures from human or natural causes that make them vulnerable are not reversed. Endangered species are threatened with immediate extinction or extirpation because of human actions.

Everyone should do their part to help Nepal to protect our wildlife resource. Now a new Nepal should give every citizen the opportunity to support conservation projects and give something back to the government.

"As we are in hope and wish to receive applications from many groups and individuals including grassroots fishing community and marginalized societies, clubs, and conservation groups.

\section{We must enjoy wild life from distance}

Captivity is sometimes tolerable, but it is seldom more desirable than freedom. This is true for man - it is also true for wild animals. Wild creatures become captives in a variety of ways; however, the environments provided are usually inferior to their natural habitats. Moreover, the harboring of wild animals results in unforeseen problems and may even represent potential dangers. Finally, when the novelty wears thin, it is frequently difficult to find an acceptable way of disposing of unwanted wildlife.

Each spring, thousands of apparently abandoned or injured infant wild animals are "rescued" by well-meaning people.

The history of injured or "abandoned" wildlife is usually unknown, and this should be reason for extreme caution.

A most tragic incident occurred during 1990 B.S. earthquake in Nepal which is recorded as MAHABHUKAMPA, the destruction of wildlife is unknown but expected a huge displacement and loss.

That would be one possible conclusion; however, a more realistic one would be to enjoy wild animals from a distance - a distance which allows them to live out their lives on their own terms where they were meant to be - in the wild.

Hunting: Kindness or cruelty?

The fact that hunters kill the animals they hunt is not an issue because all animals that are born to die. The issue then is whether by hunting the hunter reduces the animal's value of life, in terms of stress, longevity and health and, whether by hunting the hunter inflicts more suffering than would have occurred if he did not hunt. 
In today's human dominated world the cause of death among wild animals is a direct result of either a conscious or unconscious human decision. How much the animals suffer is determined directly by that decision and no one can escape their responsibility in that choice. Unlike the non-hunter, the hunter - and especially the bow-hunter - has chosen to come into direct contact with, and appreciation for, his prey and to make his decision consciously on the spot with only his own ethics and conscience to guide him.

Without hunting them - in these human dominated world-populations outgrow available food supplies.

Many studies have demonstrated that in overpopulated situations the youngest and weakest animals are driven away for short food supplies by the larger, stronger animals including their own mothers. The young are the first to die when starvation becomes the controlling factor. The price a wildlife population pays for being labeled "game" is the increased chance of being killed in the prime of life rather than slowly starving in the first year or two of life.

What of mental suffering, anxiety, fright and grief? Many writers and film makers would have us believe that animals think as human do. There is, however, little but imagination to support this.

Hunting is clearly an acceptable alternative to, rather than a cause of, unnecessary animal suffering. But is it worth talking that animal poaching and illegal transiting of wildlife products from Nepal is no longer tolerable for the benefits of all of us.

WILDLIFE HABITAT PROTECTION PROGRAMS in Nepal is young written history. In Nepal, extensive efforts have been made to protect wildlife habitats. However, while it may be feasible to bring major, significant wildlife habitat areas under government control and protection, most of Nepal's wildlife habitat resource remains in I/NGO hands.

"National Policies for the Conservation of Wildlife Habitat" recognizes the need for wildlife research and the evaluation of wildlife habitat as well as for the integration of wildlife management into the management of all resources. It also emphasizes the need for increased public awareness about the importance of wildlife and wildlife habitat. Zoo, Wildlife Reservoirs, and National Parks are all part of the Wildlife Conservation Society. Nepal Police is one of the best intervening agencies for the wildlife crime for that matter.

A lot of the "young-timers" (24 lives) are gone (Ghunsa Tragedy) but their pictures, notes and stories live on. So before the closets and trunks are cleaned out the Department of Lands and Forests is attempting to get the history of our use and enjoyment of Nepal's wildlife into a book that will be of interest to present and future generations. Late Dr. Harka Gurung professor of wildlife ecology have contributed a lot in this field that we shouldn't forget to admire.

(A Contribution of the Crime Division, Hanumandhoka, Kathmandu is thankful to prepare this article)

\section{Best wishes and greeting on the auspicious occasion of Bijaya Dashami and Dipawali 2064}

Coordination for Novel \& Creative Teamwork (CONCRETE) Kathmandu

\section{Best wishes and greeting on the auspicious occasion of Bijaya Dashami and Dipawali 2064}

Self Help Environment Awareness Camp (SHEAC) Institute of Forestry, Pokhara 